Article

\title{
Eco-Friendly Ca-Montmorillonite Grafted by Non-Acidic Ionic Liquid Used as A Solid Acid Catalyst in Cellulose Hydrolysis to Reducing Sugars
}

\author{
Yang Zhou, Miao Yang, Dongshen Tong *, Haiyan Yang and Kai Fang \\ State Key Laboratory Breeding Base of Green Chemistry Synthesis Technology, Discipline of Industrial Catalysis, \\ College of Chemical Engineering, Zhejiang University of Technology, Hangzhou 310032, China; \\ zy15958048374@163.com (Y.Z.); 2111601217@zjut.edu.cn (M.Y.); 2111701038@zjut.edu.cn (H.Y.); \\ 2111701376@zjut.edu.cn (K.F.) \\ * Correspondence: tds@zjut.edu.cn; Tel.: +86-0571-8832-0062
}

Academic Editor: Matteo Guidotti

Received: 19 April 2019; Accepted: 13 May 2019; Published: 13 May 2019

\begin{abstract}
An effective and friendly method was developed for the production of reducing sugars (RS) from the hydrolysis of cellulose over the solid catalyst of Ca-montmorillonite (Mt) grafted by non-acidic ionic liquid (Mt-IL) in water. The effect of mass ratio, water dosage, reaction temperature, and time were investigated in a batch reactor. Raw Mt showed only a 7.9\% total reducing sugars (TRS) yield for the catalytic hydrolysis of cellulose in water. As the Mt was grafted by $-\mathrm{SO}_{3} \mathrm{H}$ and IL, the TRS yield greatly increased under the same reaction conditions. The highest TRS yield of $35.7 \%$ was obtained on the catalyst of Mt grafted by non-acidic IL at $200{ }^{\circ} \mathrm{C}$ with the mass ratio of catalyst to cellulose of 0.2 for $120 \mathrm{~min}$. The high TRS yield for Mt-IL should be attributed to the synergistic effect of the dissolution of cellulose by IL and the exposed metal ions on the layer with water. Although the yield of TRS on Mt-IL decreased gradually with recycling runs, the decrease after the first run was not very serious compared to the fresh catalyst. This work provides a promising strategy for efficient cellulose hydrolysis into fine chemicals by Mt with non-acidic IL.
\end{abstract}

Keywords: montmorillonite; ionic liquid; cellulose; hydrolysis; reducing sugars

\section{Introduction}

The depletion of fossil fuel resources and global climate change have led to more and more attention on developing a series of novel chemicals based on renewable feedstocks. Many studies have been devoted to converting renewable biomass to useful chemicals and clean fuels [1-3]. Among the natural biomass, cellulosic biomass is the most abundant inedible biomass resource produced by photosynthesis from $\mathrm{CO}_{2}$ and $\mathrm{H}_{2} \mathrm{O}$. Recently, the conversion of cellulose to value-added chemicals has been extensively studied [4-6]. Since reducing sugars (RS)—mainly glucose-are platform molecules for production of other chemicals, such as 5-hydroxymethylfurfural (HMF), levulinic acid, and alkylglucosides, depolymerization of cellulose to RS plays a critical role $[7,8]$.

Cellulose is a water-insoluble aggregate of long-chain $\beta-1,4$ glucan composed of glucose monomers linked by $\beta-1,4$ glycosidic bonds. Hydrolysis of $\beta-1,4$ glycosidic bonds and decomposition of hydrogen bonds linking $\beta-1,4$ glucan chains into water-soluble saccharides are the main technology to obtain RS [9-12]. Up to now, several technologies in the hydrolysis of cellulose have been applied, such as enzyme hydrolysis, mineral acid hydrolysis, and supercritical water hydrolysis [13-15]. Generally, enzymatic hydrolysis is the most promising approach due to its low temperature and high activity, but the high cost and reuse of the enzyme inhibit its commercialization. Mineral acids are effective for cellulose hydrolysis, however, the catalyst recovery and the waste water treatment are the problems. 
Supercritical water hydrolysis is also an efficient process, but it has drawbacks, such as harsh conditions and many side-reactions [16-18]. On the contrary, due to the advantages of easy separation and recycling, hydrolysis of cellulose over heterogeneous catalysts has received greater attention in recent years [19].

Several groups have reported that cellulose was hydrolyzed in the presence of solid acid catalysts, such as Amberlyst 15 [20], heteropolyacids [21,22], magnetic solid acid catalyst [23,24], and functional carbon materials $[25,26]$. Among them, porous solid materials modified by the $-\mathrm{SO}_{3} \mathrm{H}$ groups are extensively investigated for their cheap and easy preparation $[27,28]$. Although the catalysts supported by $-\mathrm{SO}_{3} \mathrm{H}$ groups show strong acidity and high activity in the hydrolysis of cellulose, $-\mathrm{SO}_{3} \mathrm{H}$ groups are easily leaching out and lead to environmental problems. Moreover, the hydrolysis efficiency is also low due to mass transfer resistance between solid acids and insoluble cellulose in water [29]. Consequently, more effort should be devoted to developing the environmentally friendly and efficient solid acid catalysts for the hydrolysis of cellulose.

Clay minerals are a class of phyllosilicates, which are ubiquitous in nature [30]. Depending on their layer structure, high specific surface area, and ion exchange capacity, a great number of new clay-based materials have been developed with fascinating functionalities [31-33]. Among clay minerals, montmorillonite (Mt) is one of the most common 2:1 type cationic clay with highly hydrothermal stability and thermal stability [34,35]. Functional Mt has received much attention over the past decades because it is useful in many fields, including adsorption [36], catalysis [37], and separation [38]. In our previous work, acid-activated Mt had been studied for the hydrolysis of cellulose in water, which showed higher activity than that of ZSM-5, but the total reducing sugars (TRS) yield was low [39]. In the past decade, due to the interaction between $\mathrm{Cl}^{-}$of the ionic liquid (IL) and hydroxyl groups of the polysaccharides [40], IL had been widely used for the dissolution of cellulose under mild conditions [41,42]. Moreover, the acidic functionalization of IL can directly catalyze the hydrolysis of cellulose with the ability of dissolution. Recently, more and more attention has been focused on the hydrolysis of cellulose in the IL [43-45]. However, there are still some problems, such as the high cost, high viscosity, and difficulty in separation of IL [46-48]. Therefore, from the view point of green chemistry, more efficient ways should be developed for the utilization of IL.

In this work, a new heterogeneous catalyst was prepared by grafting the 1-(trimethoxy propyl silane)-3-methyl imidazolium chloride groups without acidic groups on the surface of Mt (Mt-IL). The catalytic activity and reuse of Mt-IL were examined by the hydrolysis of cellulose into RS in water. The process provided a green and efficient method for the efficient hydrolysis of cellulose catalyzed by the weakly acidic material grafted by non-acidic IL.

\section{Results and Discussion}

\subsection{Characterization of Catalysts}

The X-ray diffraction (XRD) patterns of natural and modified montmorillonites are shown in Figure 1. From Figure 1, the XRD pattern of raw Mt clearly displayed (001) diffraction peak at about $5.65^{\circ}$, indicating the basal spacing is $1.56 \mathrm{~nm}$ as calculated by Bragg's equation, and agrees with that of Ca-montmorillonite (Ca-Mt). The diffraction peaks at $17.23^{\circ}$ and $19.77^{\circ}$ were corresponding to the (003) and (020) planes, respectively. The diffraction peak at $21.83^{\circ}$ was related to the impurities, such as quartz and calcite $[49,50]$. For HMt, the diffraction peaks were almost similar with that of raw Mt, presenting that the layer structure was not destroyed after the acid treatment [51]. As the Mt was modified by $-\mathrm{SO}_{3} \mathrm{H}$ groups, the diffraction intensity of the (001) plane weakened, presenting that the crystallinity of $\mathrm{Mt}$ decreased after the modification of $-\mathrm{SO}_{3} \mathrm{H}$ groups on the surface. For $\mathrm{Mt}-\mathrm{IL}$, it was obvious that the (001) diffraction peak was shifted to the lower angle, moreover, the diffraction intensity weakened, and the width also became a broad comparison with the raw Mt. This result presented that the interlayer of Mt was intercalated by IL groups and the crystallinity of Mt decreased a lot. 


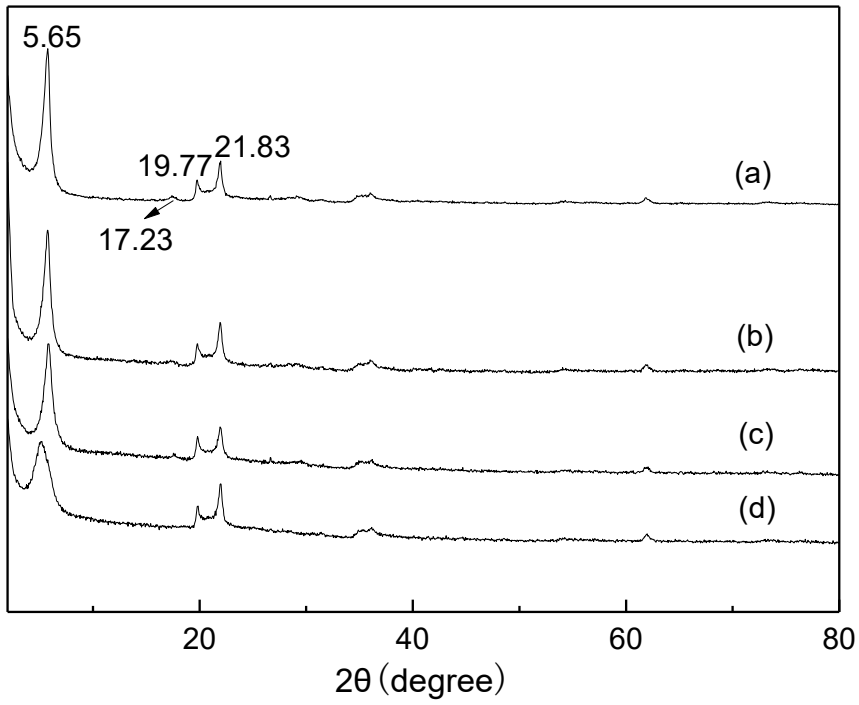

Figure 1. XRD patterns of $\mathrm{Mt}(\mathbf{a}), \mathrm{HMt}(\mathbf{b}), \mathrm{Mt}^{-\mathrm{SO}_{3} \mathrm{H}}(\mathbf{c})$, and $\mathrm{Mt}-\mathrm{IL}$ (d). IL: ionic liquid.

Figure 2 shows the Fourier transform infrared (FT-IR) spectra of IL, raw Mt, and the modified Mt. According to Figure 2, the two adsorption peaks for IL at about 3418 and $3114 \mathrm{~cm}^{-1}$ were ascribed to the aromatic $\mathrm{N}-\mathrm{H}$ and $\mathrm{C}-\mathrm{H}$, respectively. Meanwhile, it also showed the typical bands of the imidazole ring at 1600-1400 $\mathrm{cm}^{-1}$ [52]. For raw Mt, two absorption peaks around 3410 and $3628 \mathrm{~cm}^{-1}$ were ascribed to the stretching vibration of the $\mathrm{OH}$ groups. The band at about $1038 \mathrm{~cm}^{-1}$ was due to the stretching vibration of the Si-O. The bands at 525 and $466 \mathrm{~cm}^{-1}$ were attributed to the stretching and bending vibrations of Si-O-Al, respectively [51]. The FT-IR spectra of $\mathrm{HMt}$ and $\mathrm{Mt}-\mathrm{SO}_{3} \mathrm{H}$ showed the similar vibration bands with that of $\mathrm{Mt}$. It presented that $\mathrm{Al}$ cations in the octahedral layer of Mt were not leached out after the acid treatment and the structure was not destroyed. In addition, because there existed the overlap of the characteristic bands between $-\mathrm{SO}_{3} \mathrm{H}$ and $\mathrm{Mt}$, the $\mathrm{S}=\mathrm{O}$ vibration

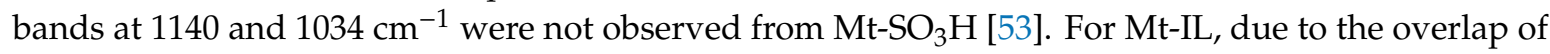
the characteristic bands between IL and $\mathrm{Mt}$, the characteristic bands belonging to the IL groups were also hardly observed, but it still showed the characteristic vibrations for the polycyclic aromatics in the $1400-1600 \mathrm{~cm}^{-1}$ region. It also presented that the $-\mathrm{SO}_{3} \mathrm{H}$ and IL groups were grafted on the surface of Mt.

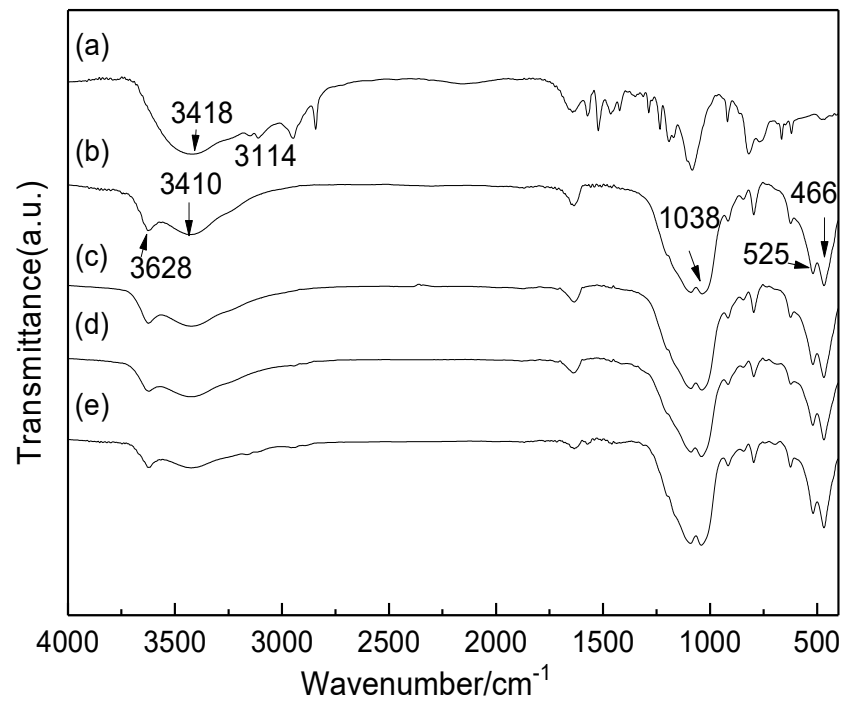

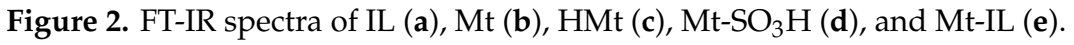


The thermal stability of the materials described above was checked by the thermogravimetric analysis (TGA) technique and their thermogravimetric (TG) and differential thermogravimetric (DTG) curves are shown in Figure 3. These materials generally showed three main peaks for loss of weight in the range $30-800{ }^{\circ} \mathrm{C}$. For $\mathrm{Mt}$, three major weight losses were observed. The maximum weight loss peaks at $70^{\circ} \mathrm{C}$ were mainly due to the volatilization of surface adsorbed water. The weight loss around $140{ }^{\circ} \mathrm{C}$ was attributed to the dehydration of interlayer water and hydrated cations on the $\mathrm{Mt}$, while the maximum weight loss peak at $640{ }^{\circ} \mathrm{C}$ was ascribed to the dehydroxylation processes [54]. When $-\mathrm{SO}_{3} \mathrm{H}$ and IL groups were introduced into the $\mathrm{Mt}$, two new peaks around 295 and $325^{\circ} \mathrm{C}$ were observed on the DTG curves of $\mathrm{Mt}-\mathrm{SO}_{3} \mathrm{H}$ and $\mathrm{Mt}-\mathrm{IL}$, which should be contributed to the decomposition of the surface's $-\mathrm{SO}_{3} \mathrm{H}$ and IL groups anchored on the surface of Mt. The fourth consecutive peak appearing between 400 and $700{ }^{\circ} \mathrm{C}$ might originate from the decomposition of siloxane groups grafted on the surface of $\mathrm{Mt}$ and the dehydroxylation on the skeleton of Mt. Obviously, in comparison with the DTG curve of $\mathrm{Mt}_{-} \mathrm{SO}_{3} \mathrm{H}$, the maximum weight loss peak of the $\mathrm{Mt}-\mathrm{IL}$ was shifted to the higher temperature in the range $400-700{ }^{\circ} \mathrm{C}$. This might be that there existed the intramolecular hydrogen bond interaction between IL and the surface $\mathrm{Si}-\mathrm{OH}$ of $\mathrm{Mt}$, which should be favorable to improving the thermal stability.
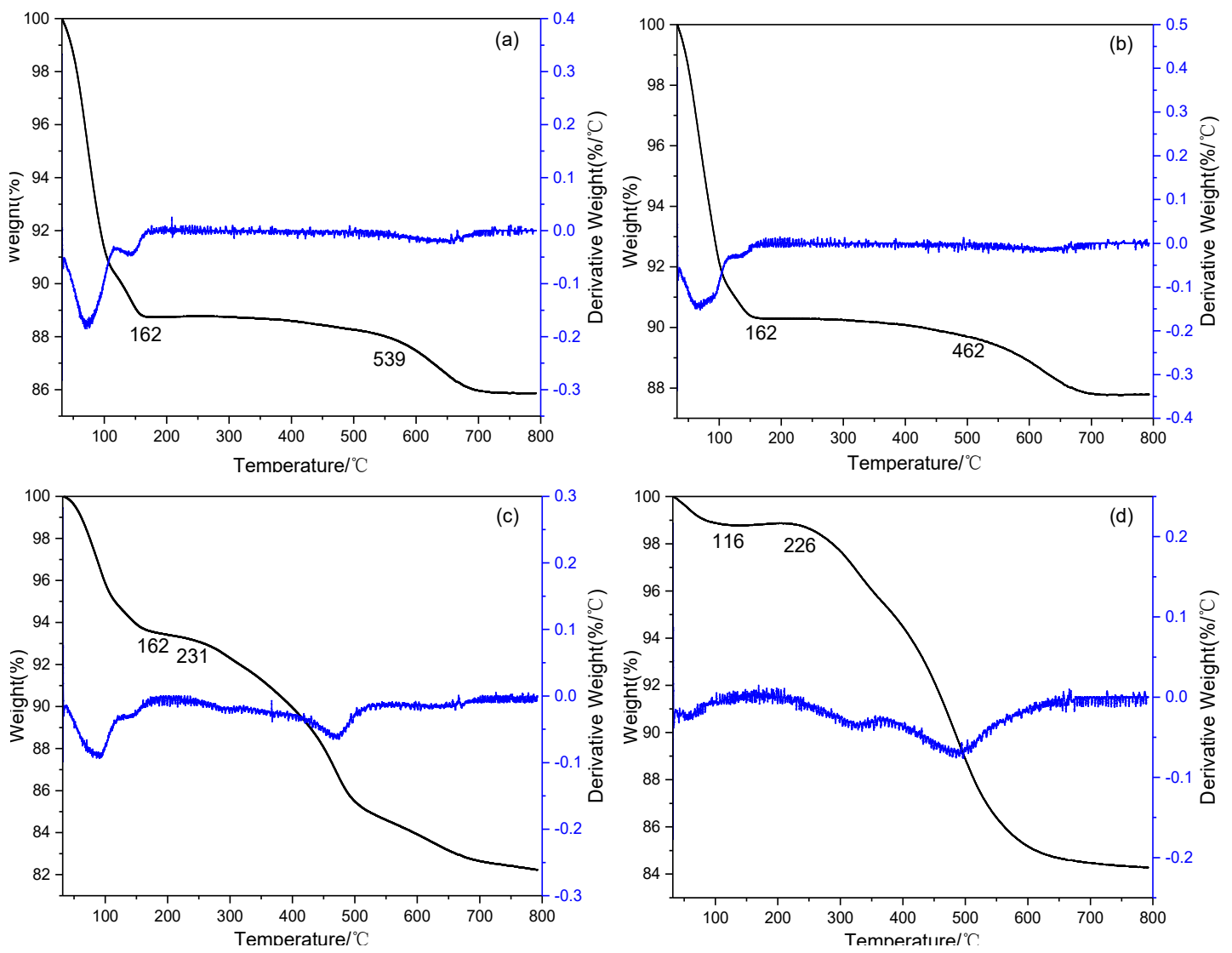

Figure 3. Thermogravimetric-differential thermogravimetric (TG-DTG) curves of Mt (a), HMt (b), $\mathrm{Mt}-\mathrm{SO}_{3} \mathrm{H}(\mathbf{c})$, and $\mathrm{Mt}-\mathrm{IL}(\mathbf{d})$.

\subsection{Hydrolysis of Cellulose}

\subsubsection{Effect of Mt Modified by Different Functional Groups in Cellulose Hydrolysis}

Table 1 shows the hydrolysis of cellulose in water catalyzed by the Mt and functional Mt. As a reference reaction, cellulose hydrolysis in water under the Mt catalyst had a TRS yield of $7.9 \%$ with the 5-HMF yield of $0.4 \%$, which should be attributed to the role of $\mathrm{H}^{+}$from the surface of Mt. It is well known that acidity is the important factor affecting the performance of the catalysts for the cellulose hydrolysis. It was obvious that the TRS yield was up to $14.4 \%$ under the acid activated Mt (entry 2), 
which should be attributed to the increase of the acidity on the catalyst. It was also interesting that although the acidic sites of $\mathrm{HMt}$ were much more than that of $\mathrm{Mt}_{-} \mathrm{SO}_{3} \mathrm{H}$ (entry 3 and 4), $\mathrm{Mt}_{-} \mathrm{SO}_{3} \mathrm{H}$ showed the higher TRS yield than HMt. It might be that the $\mathrm{H}^{+}$ions of HMt were mainly in the interlayer of $\mathrm{Mt}$ and the large cellulose molecules difficultly entered into the layer of $\mathrm{Mt}$, which led to the TRS yield decline. With the increase of the $-\mathrm{SO}_{3} \mathrm{H}$ amount on $\mathrm{Mt}-\mathrm{SO}_{3} \mathrm{H}$ samples (entry 3, 4, and 5), the TRS yield firstly increased and then changed little, and finally the highest TRS yield of $24.6 \%$ was obtained. This phenomenon could be explained by the high acidity of $\mathrm{Mt}_{-} \mathrm{SO}_{3} \mathrm{H}$ associated with the ineffective dissolution of cellulose, which results in a slower hydrolysis of cellulose into RS and then rapid degradation of cellulose to other byproducts. According to Table 1, it was fascinating that the Mt modified by non-acidic IL showed the highest TRS yield with the highest HMF yield for the hydrolysis of cellulose under water in the tested samples. Practically, negligible hydrolysis was observed for non-acidic IL, such as [BMIM][OTF] or [BMIM][Cl] [55]. It had been reported that for clay minerals, the exposed metal ions $\left(\mathrm{M}^{\mathrm{n}+}\right)$ on the ending of the layer could interact with water and formed the structure of $\mathrm{M}^{\mathrm{n}+}-\mathrm{OH}^{-}-\mathrm{H}^{+}$[56]. Therefore, in this study, the $\mathrm{H}^{+}$ions were released from $\mathrm{M}^{\mathrm{n}+}-\mathrm{OH}^{-}-\mathrm{H}^{+}$ in water, and it could be reasonably deduced that the high TRS yield for Mt-IL should be attributed to the synergistic effect of the dissolution of cellulose by IL and the exposed metal ions on the layer with water. Mt is a bio-compatible and eco-friendly material with high hydrothermal stability and thermal stability. Moreover, it is ubiquitous in nature. Thus, the novel catalyst is a promising and environmentally friendly material for cellulose hydrolysis.

Table 1. Hydrolysis of cellulose catalyzed by Mt and functional Mt in water ${ }^{\text {a. }}$

\begin{tabular}{ccccc}
\hline Entry & Catalysts & Content of Acidic Sites $\left.\mathbf{( m m o l \cdot g}^{-\mathbf{1}}\right)$ & TRS Yield (\%) & 5-HMF Yield (\%) \\
\hline 1 & $\mathrm{Mt}$ & 0.012 & 7.9 & 0.4 \\
2 & $\mathrm{HMt}$ & 0.320 & 14.4 & 1.0 \\
3 & $\mathrm{Mt}-\mathrm{SO}_{3} \mathrm{H}-1$ & 0.236 & 19.3 & 1.6 \\
4 & $\mathrm{Mt}^{-\mathrm{SO}_{3} \mathrm{H}-2}$ & 0.296 & 24.5 & 1.7 \\
5 & $\mathrm{Mt}-\mathrm{SO}_{3} \mathrm{H}-3$ & 0.532 & 24.6 & 1.8 \\
6 & $\mathrm{Mt}-\mathrm{IL}$ & 0.056 & 35.7 & 1.9 \\
\hline
\end{tabular}

a Catalyst: $0.1 \mathrm{~g}$, cellulose: $0.5 \mathrm{~g}$; water: $7.0 \mathrm{~mL}$, reaction temperature and time: $200{ }^{\circ} \mathrm{C}$ and $120 \mathrm{~min}$. TRS: total reducing sugars.

\subsubsection{Effect of Reaction Conditions on Cellulose Hydrolysis over Mt-IL}

The effect of reaction conditions, such as reaction time, temperature, and the ratio of catalyst to cellulose on the catalytic performance of Mt-IL, were investigated in order to maximize the yield of TRS. According to the reports, RS could be further transformed to other products with the increasing of reaction time, such as levulinic acid, formic acid, or coke $[57,58]$. Thus, the effect of reaction time for cellulose hydrolysis was firstly investigated at $200{ }^{\circ} \mathrm{C}$ and the results are shown in Figure 4a. According to Figure $4 a$, the yield of TRS increased obviously at the initial stage. After reaching the maximum yield of $35.7 \%$ in $120 \mathrm{~min}$, the TRS yield slowly reduced from 2.5 to $3.5 \mathrm{~h}$, which might be the conversion of the formed RS. Figure $4 \mathrm{~b}$ presents the effect of reaction temperature on TRS yield. The yield of TRS increased from $18.3 \%$ to $35.7 \%$ as the temperature was elevated from 170 to $200{ }^{\circ} \mathrm{C}$. Subsequently, the TRS yield decreased with the increasing temperature. This might be that the RS decomposed to other products or formed the coke on the surface at high temperature [39,59]. Figure $4 \mathrm{c}$ shows the effect of the weight ratio of catalyst to cellulose on the TRS yield. The TRS yield firstly increased and then decreased with the increasing of the catalyst amount. The highest yield of TRS was obtained at the mass ratio of catalyst to cellulose being 0.2. However, after the peak, the yield of TRS reduced. It should be that the redundant acid sites with the increasing of the catalyst amount boosted the transformation of the RS to other byproducts. Moreover, the agglomeration of the particles also caused the reduction of catalytic activity in a high catalyst amount. Figure $4 \mathrm{~d}$ indicates the effect of the amount of water on the TRS yield. When the amount of water was increased to $7 \mathrm{~mL}$, the concentration of hydrogen protons originated from water increased and facilitated the hydrolysis 
reaction. As the amount of water was further increased to $9 \mathrm{~mL}$, the concentration of hydrogen protons was too high in a short period and led to the conversion of the produced RS to other byproducts or coke.
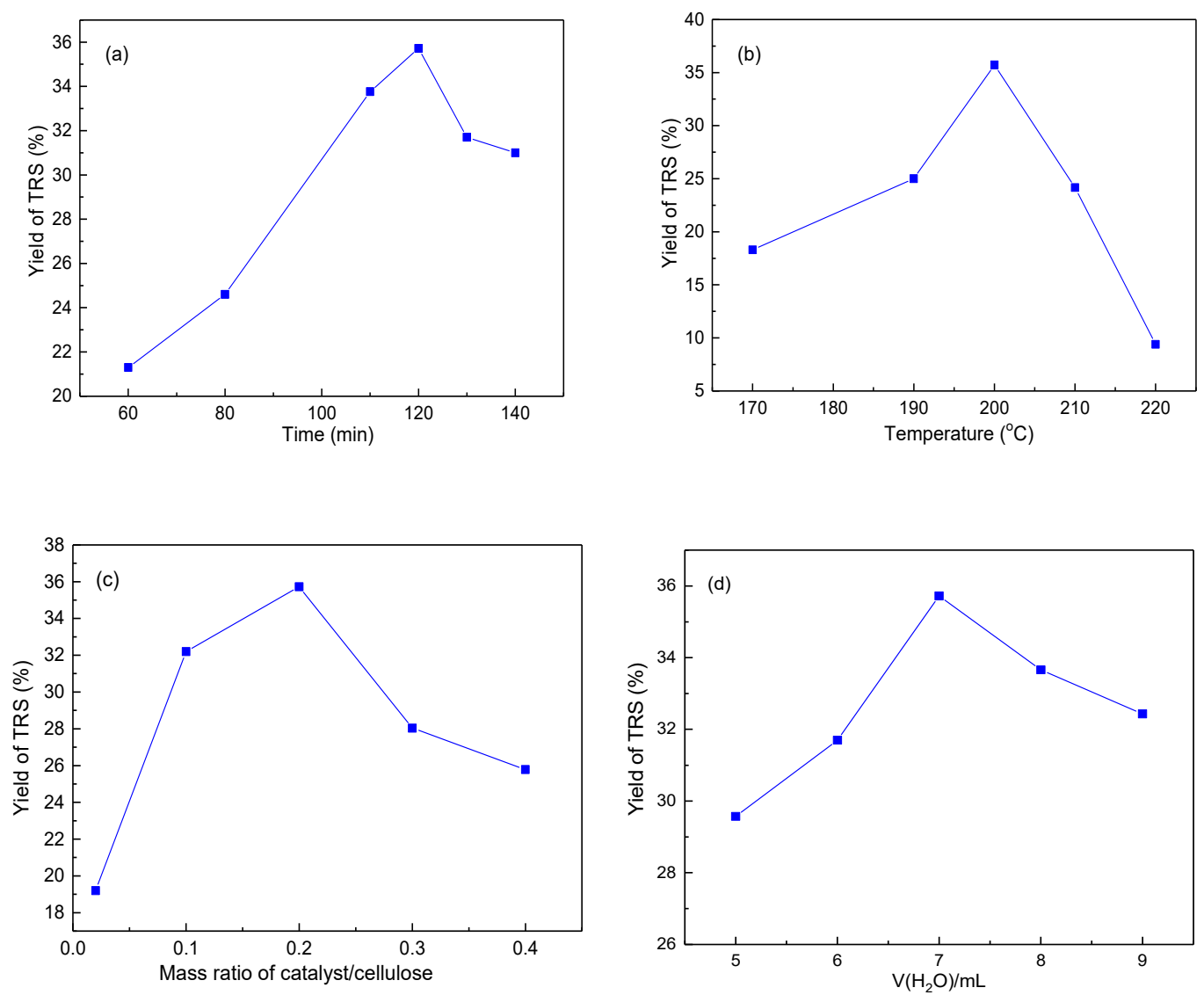

Figure 4. Effect of reaction time (a), temperature (b), weight ratio of catalysts to cellulose (c), and water dosage (d) on TRS yield over Mt-IL.

\subsubsection{Reuse of Mt-IL in Cellulose Hydrolysis}

Finally, the reuse of Mt-IL catalyst for the hydrolysis of cellulose in water was investigated under the optimum conditions and the results are shown in Figure 5. As shown in Figure 5, the yield of TRS decreased gradually with recycling times, but the decrease after the first run was not very serious compared to the fresh catalyst. In order to explore the deactivation, the structure of the used catalyst was characterized by XRD and FT-IR. The characterization results are shown in Figures 6 and 7 . According to Figure 6, the XRD pattern of the used Mt-IL showed the typical diffraction of cellulose with the reflections at $2 \theta=15.42^{\circ}$ for the (101) plane, $2 \theta=22.50^{\circ}$ for the (002) plane, and $2 \theta=34.50^{\circ}$ for the (040) plane [60]. Moreover, the (001) diffraction peak of Mt was further shifted from $5.05^{\circ}$ to $4.67^{\circ}$, presenting that the interlayer space increased. This indicated that there existed cellulose on the used Mt-IL and the interlayer of Mt was intercalated by cellulose or the products. From Figure 7, the used Mt-IL also showed the representative bands of cellulose. The absorptions at about 2900 and $1370 \mathrm{~cm}^{-1}$ are related to the stretching and bending vibration of $\mathrm{C}-\mathrm{H}$. The band at $1310 \mathrm{~cm}^{-1}$ is assigned to the symmetric bending vibration of $\mathrm{CH}_{2}$. The absorption band at $1158 \mathrm{~cm}^{-1}$ is ascribed to the $\mathrm{C}-\mathrm{O}-\mathrm{C}$ stretching vibration at the $\beta-(1,4)$-glycosidic linkages. Furthermore, the new band at $1710 \mathrm{~cm}^{-1}$ was assigned to vibration of the $\mathrm{C}=\mathrm{O}$ bond $[61,62]$. Thus, the FT-IR results also proved that cellulose existed on the surface of $\mathrm{Mt}$ and there were also some carbonyl compounds formed during the hydrolysis. Relating to the reuse results, it could be deduced that the deposition of cellulose and byproducts might 
be responsible for the deactivation of Mt-IL, and after the deposition saturation, the TRS yield changed little on the recycled catalyst.

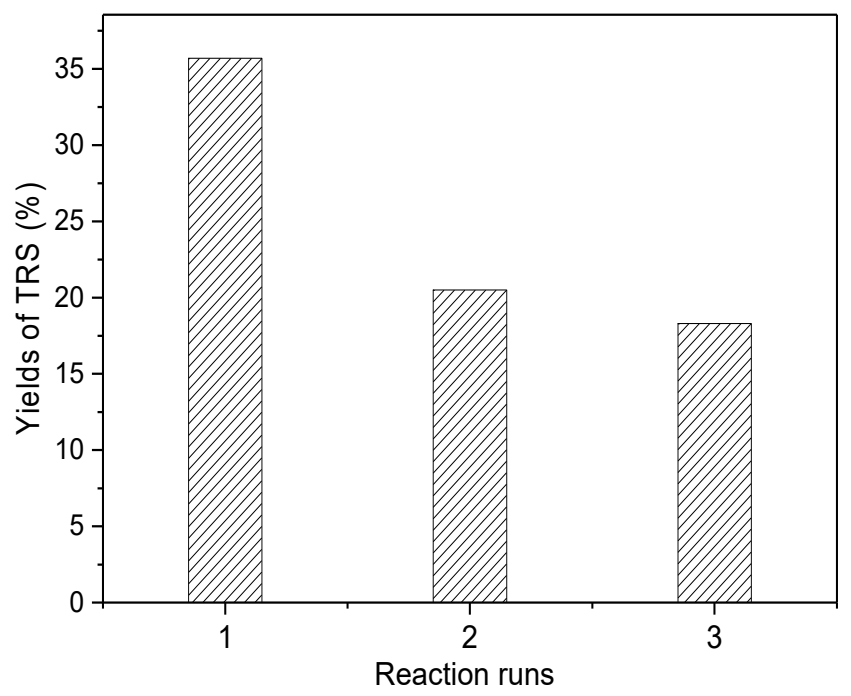

Figure 5. Reuse of Mt-IL catalyst for the cellulose hydrolysis.

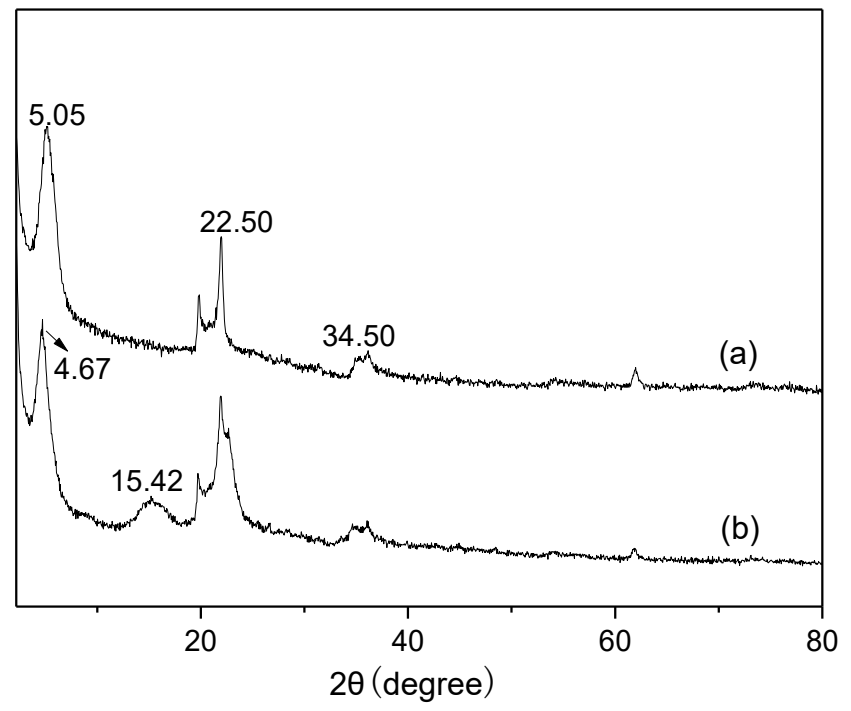

Figure 6. XRD patterns of fresh Mt-IL (a) and recycled Mt-IL after the cellulose hydrolysis (b). 


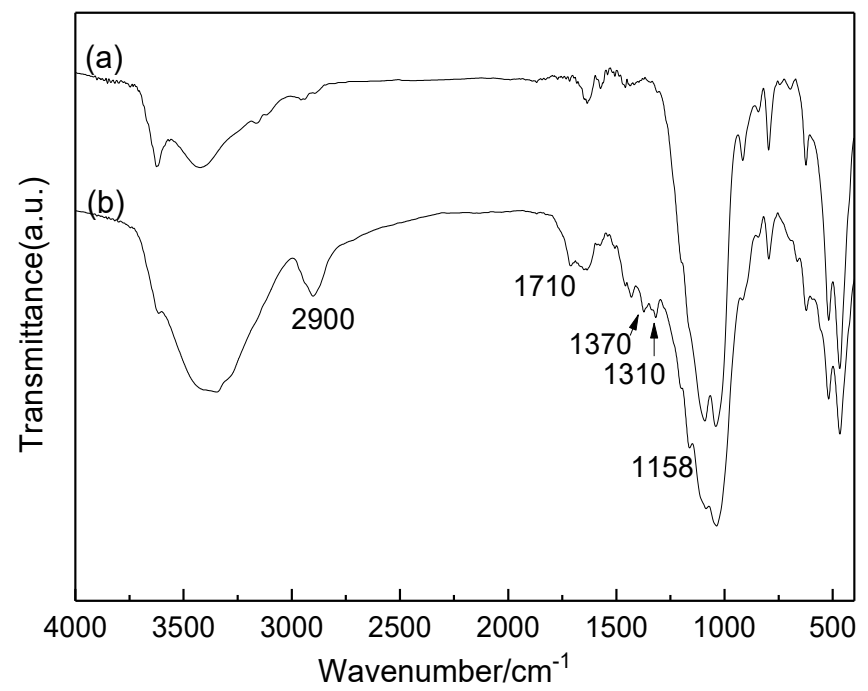

Figure 7. FT-IR spectra of fresh Mt-IL (a) and recycled Mt-IL after the cellulose hydrolysis (b).

\section{Materials and Methods}

\subsection{Materials}

The microcrystalline cellulose powder was purchased from the ShengDeLi Synthetic Leather Material Co., Ltd., Huzhou, China, and obtained from cotton. The cellulose content was above 99 wt $\%$. No physical or chemical pretreatments had been used to increase the non-crystalline cellulose fraction. The Ca-montmorillonite (Ca-Mt) was provided by Zhejiang ChangAn Renheng Science and Technology Co., Ltd., Hangzhou, China. The cation exchange capacity (CEC) of Mt was $80 \mathrm{mmol} / 100 \mathrm{~g}$. Also, 1-methyl-1H-imidazol, mercaptopropyl trimethoxysilane (MPTMS), and 3-chloropropyl trimethoxy silane were purchased from Aladdin Chemicals Co., Ltd., Shanghai, China. All other chemicals (analytic purity) were commercially available products and were used without further purification.

\subsection{Catalyst Preparation}

\subsubsection{Preparation of Acid-Activated Mt}

The purified Ca-Mt (12 g), was dispersed in $120 \mathrm{~mL} 0.5 \mathrm{wt} \% \mathrm{H}_{2} \mathrm{SO}_{4}$ and refluxed at $80{ }^{\circ} \mathrm{C}$ for $1.5 \mathrm{~h}$. Then the slurry was cooled, filtered, and washed thoroughly with distilled water three times. The product was dried at $80^{\circ} \mathrm{C}$ for $12 \mathrm{~h}$. The activated Mt was designated as HMt.

\subsubsection{Preparation of $\mathrm{Mt}-\mathrm{SO}_{3} \mathrm{H}$}

In a typical procedure, $12 \mathrm{~g} \mathrm{Ca-Mt} \mathrm{in} 360 \mathrm{~mL}$ water was stirred for $30 \mathrm{~min}$ at room temperature, and then $4 \mathrm{~mL}$ MPTMS was added into it. Finally, the mixture was stirred at $80{ }^{\circ} \mathrm{C}$ for $2.5 \mathrm{~h}$ to obtain thiol functionalized Mt (Mt-SH). Then the slurry was cooled, filtered, and washed thoroughly with anhydrous ethanol two times, and the thiol group was oxidized to sulfonic acid using $\mathrm{H}_{2} \mathrm{O}_{2}$ in the presence of ethanol at $60{ }^{\circ} \mathrm{C}$ for $4 \mathrm{~h}\left(58 \mathrm{~mL}\right.$ of $30 \% \mathrm{H}_{2} \mathrm{O}_{2}$ in $174 \mathrm{~mL}$ ethanol for $12 \mathrm{~g}$ of Mt-SH). After that, the slurry was cooled, filtered, and washed thoroughly with distilled water three times. The product was dried at $80{ }^{\circ} \mathrm{C}$ for $12 \mathrm{~h}$. The amount of $-\mathrm{SO}_{3} \mathrm{H}$ was adjusted by the concentration of MPTMS and the synthesized samples were designated as $\mathrm{Mt}_{-} \mathrm{SO}_{3} \mathrm{H}-1, \mathrm{Mt}-\mathrm{SO}_{3} \mathrm{H}-2$, and $\mathrm{Mt}-\mathrm{SO}_{3} \mathrm{H}-3$, respectively.

\subsubsection{Preparation of Mt-IL}

Firstly, 1-(trimethoxy propyl silane)-3-methyl imidazolium chloride ( $\left.\mathrm{Si}(\mathrm{MeO})_{3} \mathrm{PMIMCl}\right)$ was synthesized. Four milliliters of 1-methyl-1H-imidazol and $10 \mathrm{~mL}$ of 3-chloropropyl trimethoxy silane were mixed in $100 \mathrm{~mL}$ of toluene and the mixture stirred at the reflux temperature of toluene $\left(120^{\circ} \mathrm{C}\right)$ 
for $12 \mathrm{~h}$. Finally, the toluene was removed by rotary evaporation and an orange viscous liquid $\mathrm{Si}(\mathrm{MeO})_{3} \mathrm{PMIMCl}$ was obtained.

Then, the Ca-Mt was mixed with $\mathrm{Si}(\mathrm{MeO})_{3} \mathrm{PMIMCl}$ in anhydrous ethanol $(100 \mathrm{~mL})$ at $90{ }^{\circ} \mathrm{C}$ for $12 \mathrm{~h}$. After silanization, the precipitate was filtered and washed with distilled water three times. The product was dried at $80^{\circ} \mathrm{C}$ for $12 \mathrm{~h}$. The sample was designated as Mt-IL.

\subsection{Catalytic Conversion of Cellulose}

The hydrolysis reaction was carried out in a Teflon-lined stainless steel autoclave $(25 \mathrm{~mL})$. A certain amount of distilled water, cellulose, and catalyst were introduced into the autoclave. The reaction was carried out between 170 and $220^{\circ} \mathrm{C}$ under antogenetic pressures. After the reaction, the catalyst and the unreacted cellulose were removed by filtration. The liquid products were analyzed at $540 \mathrm{~nm}$ using 3,5-Dinitrosalicylic acid method by visible spectrophotometer manufactured by Shanghai Precision \& Science Instruments Co. Ltd. Cellulose conversions were determined by the change of cellulose weight before and after the reaction, with an uncertainty of $\pm 3 \%$. The yield of reducing sugar was calculated from the equation: yield $(\%)=$ (weight of reducing sugar in the products)/(weight of cellulose put into the reactor) $\times 100 \%$. The concentration of 5 -HMF was analyzed by a Waters 2695 series HPLC equipped with an ultraviolet detector applying an InertSustain C18 $(4.6 \mathrm{~mm} \times 250 \mathrm{~mm} \times 5 \mu \mathrm{m})$, and the yield of 5-HMF was calculated based on the calibration curves.

\subsection{Catalyst Characterization}

The X-ray diffraction (XRD) measurements were collected using a PANAlytical X'Pert PRO diffractometer between $2^{\circ}$ and $80^{\circ}(2 \theta)$ with a scanning rate of $0.1 \%$, employing $\mathrm{Cu} \mathrm{K} \alpha$ radiation $\left(\lambda=1.54056 \AA\right.$ A). Fourier transform infrared (FT-IR) spectra were recorded between 4000 and $400 \mathrm{~cm}^{-1}$ using a Nicolet 6700 Fourier transform spectrometer. The samples were dried at $110^{\circ} \mathrm{C}$, mixed with $\mathrm{KBr}$, and exposed to infrared light. The pellets were immediately measured after preparation under ambient conditions in the mid-infrared region. The spectra were the result of averaging 32 scans at wavelengths ranging from 4000 to $400 \mathrm{~cm}^{-1}$. Thermal analysis of nanocomposites was carried out using thermogravimetric-differential thermogravimetric (TG-DTG) methods on a Mettler Toledo thermobalance. TG/DTG curves were recorded with a $10{ }^{\circ} \mathrm{C} / \mathrm{min}$ heating rate under air atmosphere between 30 and $800^{\circ} \mathrm{C}$.

The measured process for acidic sites on the catalysts was described as follows: a catalyst $(0.05 \mathrm{~g})$ was treated with $0.01 \mathrm{~mol} / \mathrm{L}$ of $\mathrm{NaCl}$ solution $(20 \mathrm{~mL})$ for $1 \mathrm{~h}$ at $20-50^{\circ} \mathrm{C}$ under ultrasonic vibration. After centrifugal separation, the supernatant solution was titrated by $0.01 \mathrm{~mol} / \mathrm{L}$ of $\mathrm{NaOH}$ solution using phenolphthalein as an indicative.

\section{Conclusions}

In summary, an efficient and friendly catalyst was prepared for the hydrolysis of cellulose to reducing sugars in water. The montmorillonite grafted by non-acidic ionic liquid (Mt-IL) catalyst was active for the hydrolysis of cellulose. The highest TRS yield of $35.7 \%$ was obtained at $200{ }^{\circ} \mathrm{C}$ with the mass ratio of catalyst to cellulose of 0.2 for $120 \mathrm{~min}$ on the Mt-IL catalyst. The high TRS yield for Mt-IL should be attributed to the synergistic effect of the dissolution of cellulose by IL and the exposed metal ions on the layer with water. Although the yield of TRS on Mt-IL decreased gradually with recycling runs, its decrease was not very serious after the first run. The deposition of cellulose and byproducts might be responsible for the deactivation of Mt-IL. This work provides a promising strategy for the effective hydrolysis of cellulose into reducing sugars as well as into other chemicals in water with non-acidic IL.

Author Contributions: Conceptualization and Methodology, Y.Z. and D.T.; Data curation and Formal analysis M.Y., Y.Z., K.F., and H.Y.; Software, K.F.; investigation, H.Y.; Writing-Original Draft Preparation, Y.Z. and M.Y.; Writing-Review \& Editing, D.T. 
Funding: The authors wish to acknowledge the National Natural Scientific Foundation of China (21506188), the Natural Scientific Foundation of Zhejiang Province ZJNSF (LY16B030010), China Postdoctoral Science Foundation (2018M630688), the project from Science and Technology Department of Wenzhou (G20180017), and Project of Zhejiang "151" talents project.

Conflicts of Interest: The authors declare no conflict of interest.

\section{References}

1. Zhou, C.H.; Xia, X.; Lin, C.X.; Tong, D.S.; Beltramini, J. Catalytic conversion of lignocellulosic biomass to fine chemicals and fuels. Chem. Soc. Rev. 2011, 40, 5588-5617. [CrossRef]

2. Sweygers, N.; Alewaters, N.; Dewil, R.; Appels, L. Microwave effects in the dilute acid hydrolysis of cellulose to 5-hydroxymethylfurfural. Sci. Rep. 2018, 8, 11-15. [CrossRef]

3. Yu, J.; Wang, J.Y.; Wang, Z.; Zhou, M.D.; Wang, H.Y. Hydrolysis of cellulose promoted by silicalite-1 modified HY zeolite in 1-ethyl-3-methylimidazolium chloride. Cellulose 2018, 25, 1607-1615. [CrossRef]

4. Chen, Y.D.; Ai, X.L.; Huang, B.; Huang, M.J.; Huang, Y.; Lu, Y. Consecutive preparation of hydrochar catalyst functionalized in situ with sulfonic groups for efficient cellulose hydrolysis. Cellulose 2017, 24, 2743-2752. [CrossRef]

5. Li, O.L.; Ikura, R.; Ishizaki, T. Hydrolysis of cellulose to glucose over carbon catalysts sulfonated via a plasma process in dilute acids. Green Chem. 2017, 19, 4774-4777. [CrossRef]

6. Chu, S.; Yang, L.N.; Guo, X.C.; Dong, L.L.; Chen, X.F.; Li, Y.R.; Mu, X.D. The influence of pore structure and $\mathrm{Si} / \mathrm{Al}$ ratio of HZSM-5 zeolites on the product distributions of alpha-cellulose hydrolysis. Mol. Catal. 2018, 445, 240-247. [CrossRef]

7. Dutta, S.; Pal, S. Promises in direct conversion of cellulose and lignocellulosic biomass to chemicals and fuels: Combined solvent-nanocatalysis approach for biorefinary. Biomass Bioenerg. 2014, 62, 182-197. [CrossRef]

8. Liu, X.X.; Xu, Q.; Liu, J.Y.; Yin, D.L.; Su, S.P.; Ding, H. Hydrolysis of cellulose into reducing sugars in ionic liquids. Fuel 2016, 164, 46-50. [CrossRef]

9. Song, J.L.; Fan, H.L.; Ma, J.; Han, B.X. Conversion of glucose and cellulose into value-added products in water and ionic liquids. Green Chem. 2013, 15, 2619-2635. [CrossRef]

10. Zhang, M.; Wu, M.H.; Liu, Q.; Wang, X.; Lv, T.; Jia, L.S. Graphene oxide mediated cellulose-derived carbon as a highly selective catalyst for the hydrolysis of cellulose to glucose. Appl. Catal. A-Gen. 2017, 543, $218-224$. [CrossRef]

11. Weingarten, R.; Rodriguez-Beuerman, A.; Cao, F.; Luterbacher, J.S.; Alonso, D.M.; Dumesic, J.A.; Huber, G.W. Selective Conversion of cellulose to hydroxymethylfurfural in polar aprotic solvents. Chem. Cat. Chem. 2014, 6, 2229-2234. [CrossRef]

12. Chen, G.Z.; Wang, X.C.; Jiang, Y.J.; Mu, X.D.; Liu, H.C. Insights into deactivation mechanism of sulfonated carbonaceous solid acids probed by cellulose hydrolysis. Catal. Today 2019, 319, 25-30. [CrossRef]

13. Palkovits, R.; Tajvidi, K.; Procelewska, J.; Rinaldi, R.; Ruppert, A. Hydrogenolysis of cellulose combining mineral acids and hydrogenation catalysts. Green Chem. 2010, 12, 972-978. [CrossRef]

14. Hammerer, F.; Loots, L.; Do, J.L.; Therien, J.P.D.; Nickels, C.W.; Friscic, T.; Auclair, K. Solvent-free enzyme activity: Quick, high-yielding mechanoenzymatic hydrolysis of cellulose into glucose. Angew. Chem.-Int. Edit. 2018, 57, 2621-2624. [CrossRef]

15. Buffiere, J.; Ahvenainen, P.; Borrega, M.; Svedstrom, K.; Sixta, H. Supercritical water hydrolysis: A green pathway for producing low-molecular-weight cellulose. Green Chem. 2016, 18, 6516-6525. [CrossRef]

16. Huang, Y.B.; Fu, Y. Hydrolysis of cellulose to glucose by solid acid catalysts. Green Chem. 2013, 15, $1095-1111$. [CrossRef]

17. Van, D.V.S.; Geboers, J.; Jacobs, P.A.; Sels, B.F. Recent advances in the catalytic conversion of cellulose. Chem. Cat. Chem. 2011, 3, 82-94.

18. Chang, J.K.W.; Duret, X.; Berberi, V.; Zahedi-Niaki, H.; Lavoie, J.M. Two-Step Thermochemical Cellulose Hydrolysis With Partial Neutralization for Glucose Production. Front. Chem. 2018, 6, 117-128. [CrossRef]

19. Shen, F.; Smith, R.L.; Li, L.Y.; Yan, L.L.; Qi, X.H. Eco-friendly method for efficient conversion of cellulose into levulinic acid in pure water with cellulase-mimetic solid acid catalyst. ACS Sustain. Chem. Eng. 2017, 5, 2421-2427. [CrossRef] 
20. Lanzafame, P.; Temi, D.M.; Perathoner, S.; Spadaro, A.N.; Centi, G. Direct conversion of cellulose to glucose and valuable intermediates in mild reaction conditions over solid acid catalysts. Catal. Today 2012, 179, 178-184. [CrossRef]

21. Tian, J.; Wang, J.H.; Zhao, S.; Jiang, C.Y.; Zhang, X.; Wang, X.H. Hydrolysis of cellulose by the heteropoly acid $\mathrm{H}_{3} \mathrm{PW}_{2} \mathrm{O}_{40}$. Cellulose 2010, 17, 587-594. [CrossRef]

22. Almohalla, M.; Rodriguez-Ramos, I.; Ribeiro, L.S.; Orfao, J.J.; Pereira, M.F.R.; Guerrero-Ruiz, A. Cooperative action of heteropolyacids and carbon supported Ru catalysts for the conversion of cellulose. Catal. Today 2018, 301, 65-71. [CrossRef]

23. Xiong, Y.; Zhang, Z.; Wang, X.; Liu, B.; Lin, J. Hydrolysis of cellulose in ionic liquids catalyzed by a magnetically-recoverable solid acid catalyst. Chem. Eng. J. 2014, 235, 349-355. [CrossRef]

24. Hu, L.; Wu, Z.; Xu, J.; Zhou, S.; Tang, G. Efficient hydrolysis of cellulose over a magnetic lignin-derived solid acid catalyst in 1-butyl-3-methylimidazolium chloride. Korean J. Chem. Eng. 2016, 33, 1232-1238. [CrossRef]

25. Shrotri, A.; Kobayashi, H.; Fukuoka, A. Cellulose Depolymerization over heterogeneous catalysts. Accounts Chem. Res. 2018, 51, 761-768. [CrossRef]

26. Zhang, B.; Chen, B.; Douthwaite, M.; Liu, Q.; Zhang, C.; Wu, Q.; Hutchings, G. Macroporous-mesoporous carbon supported Ni catalysts for the conversion of cellulose to polyols. Green Chem. 2018, 20, 3634-3642. [CrossRef]

27. Li, H.X.; Zhang, X.H.; Wang, Q.; Zhang, K.; Cao, Q.; Jin, L.E. Preparation of the recycled and regenerated mesocarbon microbeads-based solid acid and its catalytic behaviors for hydrolysis of cellulose. Bioresour. Technol. 2018, 270, 166-171. [CrossRef]

28. Shen, F.; Guo, T.M.; Bai, C.X.; Qiu, M.; Qi, X.H. Hydrolysis of cellulose with one-pot synthesized sulfonated carbonaceous solid acid. Fuel Process. Technol. 2018, 169, 244-247. [CrossRef]

29. Su, J.L.; Qiu, M.; Shen, F.; Qi, X.H. Efficient hydrolysis of cellulose to glucose in water by agricultural residue-derived solid acid catalyst. Cellulose 2018, 25, 17-22. [CrossRef]

30. Zhang, D.; Zhou, C.H.; Lin, C.X.; Tong, D.S.; Yu, W.H. Synthesis of clay minerals. Appl. Clay Sci. 2010, 50, 1-11. [CrossRef]

31. Saikia, P.K.; Sarmah, P.P.; Borah, B.J.; Saikia, L.; Saikia, K.; Dutta, D.K. Stabilized $\mathrm{Fe}_{3} \mathrm{O}_{4}$ magnetic nanoparticles into nanopores of modified montmorillonite clay: A highly efficient catalyst for the Baeyer-Villiger oxidation under solvent free conditions. Green Chem. 2016, 18, 2843-2850. [CrossRef]

32. Ruiz-Hitzky, E.; Sobral, M.M.C.; Gomez-Aviles, A.; Nunes, C.; Ruiz-Garcia, C.; Ferreira, P.; Aranda, P. Clay-graphene nanoplatelets functional conducting composites. Adv. Funct. Mater. 2016, 26, 7394-7405. [CrossRef]

33. Wang, Q.Y.; Wang, Y.X.; Chen, L.Y. A green composite hydrogel based on cellulose and clay as efficient absorbent of colored organic effluent. Carbohydr. Polym. 2019, 210, 314-321. [CrossRef] [PubMed]

34. Oh, J.M.; Biswick, T.T.; Choy, J.H. Layered nanomaterials for green materials. J. Mater. Chem. 2009, 19, 2553-2563. [CrossRef]

35. Kaur, M.; Arshad, M.; Ullah, A. In-situ nanoreinforced green bionanomaterials from natural keratin and montmorillonite (MMT)/cellulose nanocrystais (CNC). ACS Sustain. Chem. Eng. 2018, 6, 1977-1987. [CrossRef]

36. Zhou, C.H.; Zhang, D.; Tong, D.S.; Wu, L.M.; Yu, W.H.; Ismadji, S. Paper-like composites of cellulose acetate-organo-montmorillonite for removal of hazardous anionic dye in water. Chem. Eng. J. 2012, 209, 223-234. [CrossRef]

37. Bonacci, S.; Nardi, M.; Costanzo, P.; De, N.A.; Di, G.M.L.; Oliverio, M.; Procopio, A. Montmorillonite K10-catalyzed solvent-free conversion of furfural into cyclopentenones. Catalysts 2019, 9, 301. [CrossRef]

38. Mokhtarani, B.; Musavi, J.; Parvini, M. Extraction of toluene from alkane using BMIM NO 3 or $\mathrm{OMIM} \mathrm{NO}_{3}$ ionic liquid at $298.15 \mathrm{~K}$ and atmospheric pressure. Fluid Phase Equilib. 2014, 363, 41-47. [CrossRef]

39. Tong, D.S.; Xia, X.; Luo, X.P.; Wu, L.M.; Lin, C.X.; Yu, W.H.; Zhou, C.H.; Zhong, Z.K. Catalytic hydrolysis of cellulose to reducing sugar over acid-activated montmorillonite catalysts. Appl. Clay Sci. 2013, 74, 147-153. [CrossRef]

40. Nino, D.A.; Merino, P.; Algieri, V.; Nardi, M.; Gioia, D.M.L.; Russo, B.; Tallarida, M.A.; Maiuolo, L. Synthesis of 1,5-functionalized 1,2,3-triazoles using ionic liquid/iron(III) chloride as an efficient and reusable homogeneous catalyst. Catalysts 2018, 8, 364-377. 
41. Zhang, Y.T.; Du, H.B.; Qian, X.H.; Chen, E.Y.X. Ionic liquid-water mixtures: Enhanced K-w for efficient cellulosic biomass conversion. Energy Fuels 2010, 24, 2410-2417. [CrossRef]

42. Moreau, C.; Finiels, A.; Vanoye, L. Dehydration of fructose and sucrose into 5-hydroxymethylfurfural in the presence of 1-H-3-methyl imidazolium chloride acting both as solvent and catalyst. J. Mol. Catal. A-Chem. 2006, 253, 165-169. [CrossRef]

43. Vu, A.; Wickramasinghe, S.R.; Qian, X.H. Polymeric solid acid catalysts for lignocellulosic biomass fractionation. Ind. Eng. Chem. Res. 2018, 57, 4514-4525. [CrossRef]

44. Gioia, D.M.L.; Costanzo, P.; Nino, D.A.; Maiuolo, L.; Nardi, M.; Olivito, F.; Procopio, A. Simple and efficient Fmoc removal in ionic liquid. Rsc. Adv. 2017, 7, 36482-36491. [CrossRef]

45. Moyer, P.; Smith, M.D.; Abdoulmoumine, N.; Chmely, S.C.; Smith, J.C.; Petridis, L.; Labbe, N. Relationship between lignocellulosic biomass dissolution and physicochemical properties of ionic liquids composed of 3-methylimidazolium cations and carboxylate anions. Phys. Chem. Chem. Phys. 2018, 20, 2508-2516. [CrossRef]

46. Yu, J.L.; Maliutina, K.; Tahmasebi, A. A review on the production of nitrogen-containing compounds from microalgal biomass via pyrolysis. Bioresour. Technol. 2018, 270, 689-701. [CrossRef]

47. Lopes, A.M.D.; Bogel-Lukasik, R. Acidic ionic liquids as sustainable approach of cellulose and lignocellulosic biomass conversion without additional catalysts. ChemSusChem 2015, 8, 947-965. [CrossRef]

48. Shuai, L.; Pan, X.J. Hydrolysis of cellulose by cellulase-mimetic solid catalyst. Energy Environ. Sci. 2012, 5, 6889-6894. [CrossRef]

49. Chipera, S.J.; Bish, D.L. Baseline studies of the clay minerals society source clays: Powder X-ray diffraction analyses. Clay Clay Min. 2001, 49, 398-409. [CrossRef]

50. Viani, A.; Gaultieri, A.F.; Artioli, G. The nature of disorder in montmorillonite by simulation of X-ray powder patterns. Am. Miner. 2002, 87, 966-975. [CrossRef]

51. Zatta, L.; Ramos, L.P.; Wypych, F. Acid-activated montmorillonites as heterogeneous catalysts for the esterification of lauric acid acid with methanol. Appl. Clay Sci. 2013, 80, 236-244. [CrossRef]

52. Zhang, C.; Fu, Z.H.; Liu, Y.C.; Dai, B.H.; Zou, Y.H.; Gong, X.L.; Wang, Y.L.; Deng, X.L.; Wu, H.T.; Xu, Q.; et al. Ionic liquid-functionalized biochar sulfonic acid as a biomimetic catalyst for hydrolysis of cellulose and bamboo under microwave irradiation. Green Chem. 2012, 14, 1928-1934. [CrossRef]

53. Wilson, K.; Lee, A.F.; Macquarrie, D.J.; Clark, J.H. Structure and reactivity of sol-gel sulphonic acid silicas. Appl. Catal. A-Gen. 2002, 228, 127-133. [CrossRef]

54. Cavani, F.; Trifiro, F.; Vaccari, A. Hydrotalcite-type anionic clays: Preparation, properties and applications. Catal. Today 1991, 11, 173-301. [CrossRef]

55. Brandt, A.; Ray, M.J.; To, T.Q.; Leak, D.J.; Murphy, R.J.; Welton, T. Ionic liquid pretreatment of lignocellulosic biomass with ionic liquid-water mixtures. Green Chem. 2011, 13, 2489-2499. [CrossRef]

56. Johns, W.D. Clay mineral catalysis and petroleum generatio. Annu. Rev. Earth Planet Sci. 1979, 7, $183-198$. [CrossRef]

57. Ramli, N.A.S.; Amin, N.A.S. Catalytic hydrolysis of cellulose and oil palm biomass in ionic liquid to reducing sugar for levulinic acid production. Fuel Process. Technol. 2014, 128, 490-498. [CrossRef]

58. Chen, T.L.; Xiong, C.R.; Tao, Y.S. Enhanced Hydrolysis of cellulose in ionic liquid using mesoporous ZSM-5. Molecules 2018, 23, 10. [CrossRef] [PubMed]

59. Hu, L.; Wu, Z.; Xu, J.X.; Sun, Y.; Lin, L.; Liu, S.J. Zeolite-promoted transformation of glucose into 5-hydroxymethylfurfural in ionic liquid. Chem. Eng. J. 2014, 244, 137-144. [CrossRef]

60. Sun, Y.; Zhuang, J.P.; Lin, L.; Ouyang, P.K. Clean conversion of cellulose into fermentable glucose. Biotechnol. Adv. 2009, 27, 625-632. [CrossRef] [PubMed]

61. Cao, Y.; Tan, H.M. Structural characterization of cellulose with enzymatic treatment. J. Mol. Struct. 2004, 705, 189-193. [CrossRef]

62. Oh, S.Y.; Yoo, D.I.; Shin, Y.; Kim, H.C.; Kim, H.Y.; Chung, Y.S.; Park, W.H.; Youk, J.H. Crystalline structure analysis of cellulose treated with sodium hydroxide and carbon dioxide by means of $\mathrm{X}$-ray diffraction and FTIR spectroscopy. Carbohydr. Res. 2005, 340, 2376-2391. [CrossRef] [PubMed]

Sample Availability: Samples of the compounds are available from the authors. 
(C) 2019 by the authors. Licensee MDPI, Basel, Switzerland. This article is an open access article distributed under the terms and conditions of the Creative Commons Attribution (CC BY) license (http://creativecommons.org/licenses/by/4.0/). 